\title{
EL BURDEL COMO ESPACIO DE SOCIABILIDAD
}

por

\author{
JEAN-LOUIS GUEREÑA \\ CIREMIA, Université François Rabelais, Tours
}

RESUMEN: A pesar de que se ba podido apuntar en varias ocasiones la estrecha relación existente entre sociabilidad masculina y universo prostitucional, los historiadores de la sociabilidad en la España contemporánea, y en particular de la sociabilidad popular, han privilegiado otras formas más reconocidas y legítimas como objeto de estudio, tales como los círculos de recreo, los orfeones, las sociedades de socorros mutuos o las agrupaciones de trabajadores. Nos proponemos pues analizar aquí el espacio prostitucional en sus distintas variantes (pero principalmente la del burdel tolerado con buéspedas fijas) como un espacio de sociabilidad masculina (para los clientes, con el rito de la visita colectiva a la «casa de putas» y el «salón» del prostíbulo como espacio de recreo) pero también de sociabilidad femenina (entre prostitutas, intentando aproximarnos a la vida cotidiana en el burdel).

Palabras clave: Burdel. España. Prostitución. Sexualidad. Siglos XIX y XX. Sociabilidad.

ABSTRACT: Despite the fact that the close relation between masculine sociability and the world of prostitution bas often been pointed out, bistorians of sociability in modern Spain, and in particular popular sociability, have privileged better recognized and more legitimate forms as the object of study. Among them are recreation circles, choral societies, mutual aid societies and workers' associations. The intention of this article is to analyze the space of prostitution in its different forms (but principally that of the tolerated brotbel with established prostitutes) as a space of masculine sociability (for clients, with the rite of the collective visit to the whorehouse and the salon of the brotbel as a space of leisure) but also of feminine sociability between prostitutes, thereby examining daily life in the brotbel.

KEY WORDS: Brothel. Spain. Prostitution. Sexuality. Nineteenth century. Twentieth century. Sociability. 
Se ha podido apuntar en varias ocasiones, y por lo menos desde 1978, particularmente dentro de la historiografía francesa - en la cual se fraguó en la década de los sesenta, con Maurice Agulhon a la cabeza, la noción de sociabilidad aplicada a los estudios históricos ${ }^{1}$ - la estrecha relación existente entre espacios y formas de sociabilidad masculina y universo prostitucional ${ }^{2}$ :

«On sait bien aujourd'hui que sans l'étude du bordel, envers du «monde» mais qui participe de l'image du cercle bourgeois, l'histoire des formes de sociabilité demeurerait très incomplète, et sans doute aussi celle de la configuration affective des hommes de ce temps»3.

Pese a ello, los historiadores de la sociabilidad en la España contemporánea, y en particular de la sociabilidad popular entre los cuales nos contamos, han privilegiado desde finales de la década de los ochenta otras formas más reconocidas y supuestamente más legítimas como objeto de estudio, tales como los casinos y los círculos de recreo, los ateneos y las sociedades de instrucción, los orfeones y las sociedades corales, las sociedades de socorros mutuos y las agrupaciones de trabajadores ${ }^{4}$.

Por ello, en un estimulante artículo programático publicado en 1993, el historiador barcelonés Enric Ucelay-Da Cal, junto a algunas otras afirmaciones más discutibles, incluía precisamente la casa de prostitución (la casa de barrets) entre los espacios de sociabilidad masculina como un espacio "polivalente», llamando la atención hacia los «consumidores», los gran ausentes de la historiografía sobre la prostitución ${ }^{5}$. Va a ser la demanda masculina, subrayaba,

1 GUEREÑA, Jean-Louis: «Un ensayo empírico que se convierte en un proyecto razonado: Notas sobre la historiografía de la sociabilidad», en VALín, Alberto (Ed.): La sociabilidad en la Historia contemporánea. Reflexiones teóricas y ejercicios de análisis, Ourense, Duen de Bux (Historia. Estudios -1), 2001, pp. 13-29.

2 Corbin, Alain: Les filles de noce. Misère sexuelle et prostitution $\left(19^{e}\right.$ et $20^{e}$ siècles), Paris, AubierMontaigne (Collection historique), 1978, pp. 93-99.

3 CORBIN, Alain: «La mauvaise éducation de la prostituée au $\mathrm{XIX}^{\mathrm{e}}$ siècle», Bulletin de la Société d'bistoire moderne, Paris, $\mathrm{n}^{\circ} .34,1987$, texto recogido en Le temps, le désir et l'horreur. Essais sur le dixneuvième siècle, Paris, Aubier (Collection Historique), 1991, p. 112. Ver también CoRBIN, Alain: «Le temps des maisons closes", L'Histoire, Paris, ${ }^{\circ}$ 264, Abril de 2002, p. 51, y ALLENDER, Roland: Prostitution citadine. L'exemple de Douai, Saint-Cyr sur Loire, Éditions Alan Sutton, 2002, p. 74.

4 BreY, Gérard, Guereña, Jean-Louis, LÉCUYER, Marie-Claude, MAURICE, Jacques, Morales, Manuel, RALLE, Michel: «La sociabilidad en la España contemporánea», Estudios de Historia Social, Madrid, $\mathrm{n}^{\circ}$ 50-51, Julio-diciembre de 1989, pp. 131-305. Ver CANAL I MORELL, Jordi: «La sociabilidad en los estudios sobre la España contemporánea: una revisión", en MAZA ZORRILLA, Elena (Ed.): Sociabilidad en la España contemporánea. Historiografía y problemas metodológicos, Valladolid, Universidad de Valladolid, 2002, pp. 35-55, y las observaciones de URíA, Jorge: «Lugares para el ocio. Espacio público y espacios recreativos en la Restauración española», Historia Social, Valencia, n 41, 2001, p. 107.

5 UCELAY-DA CAL, Enric: «Els espais de la sociabilitat: La parròquia, els "parroquians» i la qüestió de les clienteles», L'Avens, Barcelona, no 171, Junio de 1993, pp. 18-27 (especialmente pp. 24-26: «La «casa de barrets» vista pels consumidors»). 
«per satisfer addiccions - sexe, beguda, jocs forts i altres sensacions, àdhuc menjars», la que irá creando un espacio alternativo «de trobada alhora estimulant i relaxat».

Nos proponemos pues analizar aquí el espacio prostitucional en sus distintas variantes (pero principalmente la del burdel tolerado con huéspedas fijas) como un espacio específico de sociabilidad masculina en la España contemporánea (para los clientes, en particular con el rito de la visita colectiva a la «casa de putas» así como el "salón» del prostíbulo enfocado como espacio de recreo) pero también de sociabilidad femenina (entre prostitutas, intentando aproximarnos a la vida cotidiana en el burdel). Tras un repaso a la historiografía existente, utilizaremos para ello de preferencia algunos documentos de archivo y testimonios publicados recientemente en libros de memorias.

\section{PROSTITUCIÓN Y SOCIABILIDAD. AlgUNOS APUNTES SOBRE LA HISTORIO- GRAFÍA ESPAÑOLA}

Efectivamente, raras veces los estudios sobre la historia de la prostitución en la España contemporánea han abordado detalladamente esta relación entre prostitución y sociabilidad, aunque podamos citar algunas aproximaciones interesantes al tema, particularmente en el marco de aportaciones locales ${ }^{6}$.

Transformación de una tesis doctoral leída en 1985, la interesante monografía de Alberto Ramos Santana sobre la burguesía gaditana en la época isabelina abordaba de paso en 1987 la prostitución en el capítulo dedicado a «Moralidad y seguridad pública» ${ }^{7}$. Trayendo a colación los testimonios de Antonio Alcalá Galiano [1789-1865] y de Federico Rubio Galí [1827-1902], ya señalaba el papel de las casas de prostitución - con distintas denominaciones («casas de citas", "casas de mala nota", "casas de alcahuetes", "casas de mala fama») como lugares de sociabilidad. Valiéndose de varios legajos del Archivo Diocesano de Cádiz, presentaba una primera relación de estas casas con la ubicación correspondiente. Su proliferación (real o apercibida como tal) dio lugar a una polémica en la prensa local en agosto de 1861 para conseguir el cierre de algunas casas de prostitución en la ciudad, obteniendo aparentemente satisfacción.

Otra excepción más notable la constituye el artículo del hispanista francés Serge Salaün, publicado primero en francés en 1994 y en español en 1999, sobre la intensa y variada actividad prostitucional desarrollada en la antigua

6 GUEREÑA, Jean-Louis: «De historia prostitutionis. La prostitución en la España contemporánea», Ayer, Madrid, $\mathrm{n}^{\circ} 25$ [Pobreza, Beneficiencia y Política Social, Ed. por Esteban DE VeGA, Mariano], 1997, pp. 35-72, y VÁZQUEZ, Francisco J.: «Los estudios históricos sobre la prostitución en la España contemporánea", en VÁzQueZ, Francisco J. (Ed.): Mal menor. Políticas y representaciones de la prostitución Siglos XVI-XIX, Cádiz, Publicaciones de la Universidad de Cádiz, 1998, pp. 137-168.

7 Ramos SANTANA, Alberto: La burguesía gaditana en la época isabelina, Cádiz, Fundación Municipal de Cultura, 1987, pp. 421-443. 
localidad minera de La Unión (Murcia), «El Eldorado Español», entre finales del siglo XIX y los años veinte del siglo $\mathrm{XX}^{8}$. Junto con los trabajos de Francisco López Villarejo sobre el enclave minero de Linares (Jaén) ${ }^{9}$, Serge Salaün nos proporciona un cuadro bastante completo del modo en que el mundo de la prostitución configuraba un tipo específico de sociabilidad obrera, la de los mineros en este caso. La rica documentación conservada en el Archivo Municipal de La Unión le permitió en efecto rastrear la gran diversidad de los lugares y de la oferta prostitucional en un microcosmos como lo es una ciudad minera: pupilas en casas de prostitución, camareras, prostitutas clandestinas, «artistas» diversas (cupletistas, bailarinas...):

«La prostitución, tal como se puede observar en La Unión, debe concebirse como una auténtica cultura, vinculada con una sociabilidad compleja, que abarca una red de consumos, de ocios y de comportamientos, una cultura a la vez privada y pública, espontánea y organizada, que tiene unas raíces sociales, profesionales, económicas, etc. Será lo que explique el carácter masivo del consumo sexual venal, la lentitud de la evolución de las mentalidades en todas las clases y hasta cierta resignación o hábito ante la amenaza de las enfermedades» ${ }^{10}$.

Por su parte, trabajando sobre la prostitución en Sevilla, Andrés Moreno Mengíbar y Francisco Vázquez García proponían analizar en 1990 el espacio de la «casa tolerada» como forma de sociabilidad masculina que se habría visto cuestionada por los reformistas españoles desde fines del siglo XIX al extenderse un nuevo discurso sobre el papel civilizador que debía desempeñar la familia ${ }^{11}$. Y en su magnífico libro publicado en 1996, síntesis y ampliación de varios de sus trabajos anteriores, Poder y prostitución en Sevilla, ambos autores demostraban claramente a propósito de la topografía de la prostitución hispalense, mapa de la ciudad en mano, la elevada concordancia entre espacio prostitucional y espacio festivo, concluyendo:

8 SALAÜN, Serge: «Les corps du mineur (Sexualité et prostitution à La Unión)», en CARRASCO, Raphaël (Ed.): La prostitution en Espagne de l'époque des Rois Catboliques à la II République, Paris, Les Belles Lettres (Annales Littéraires de l'Université de Besançon, 526), 1994, pp. 315-332, y «El cuerpo del minero. Prostitución y sexualidad en La Unión», Historiar, Barcelona, $\mathrm{n}^{\circ} 2$, Julio de 1999 [La prostitución en la España contemporánea, Ed. por GUEREÑA, Jean-Louis], pp. 35-51.

9 LÓPEZ VILL_AREJO, Francisco: «Sociedad y prostitución en un enclave minero de la Andalucía del siglo XIX», en Comunicaciones presentadas al XI Congreso de Profesores-Investigadores. Palos de la Frontera, Septiembre 1992, Córdoba, Asociación de Profesores de Geografía e Historia de Bachillerato de Andalucía «Hespérides», 1994, pp. 353-365, y «Prostitución y clases sociales en un núcleo minero de la Andalucía del siglo XIX", Bulletin d'Histoire Contemporaine de lEspagne, Aix-en-Provence, $\mathrm{n}^{\circ}$ 25, Junio de 1997 [Prostitución y sociedad en España. Siglos XIX y XX, Ed. por GuEREÑA, Jean-Louis], pp. 103-118.

10 SALAÜN, Serge: «El cuerpo del minero", op. cit., pp. 50-51.

11 Moreno Mengíbar Andrés y VÁzquez García, Francisco: «Biopolíticas del placer en España. Documentos sobre la prostitución en Sevilla ( $2^{a}$ parte): las reglamentaciones del siglo XIX", Er. Revista de Filosofía, Sevilla, nº 11, Invierno 90-91, pp. 153-192. 
«Definitivamente, las sociabilidades festivas masculinas y el meretricio formaban parte de un mismo decorado. El tiempo del ocio, cuando se invierten las rutinas de las labores y los días, y el del sexo venal, cuando se transgreden los roles conyugales, venían a encontrarse en los mismos enclaves» ${ }^{12}$.

En unas Jornadas sobre los espacios de sociabilidad sevillana verificadas en 1997, Francisco Vázquez García intentaba analizar también el burdel como medio de sociabilidad femenina, siempre a propósito del caso sevillano, a la vez que insistía de nuevo sobre la cuestión de la topografía prostitucional y su larga estabilidad desde la segunda mitad del siglo XIX ${ }^{13}$.

Por nuestra parte, hemos intentado mostrar cómo la reglamentación de la prostitución, en sus dos dimensiones (higiénica y policial), formaba claramente parte del dispositivo social construido a partir de la época isabelina ${ }^{14}$. Se trataba de una real operación de limpieza urbana paralela a la que también se realizaba entonces para con los pobres y los «vagos» para construir nuevos espacios de sociabilidad urbana. En vez de encerrar a la prostituta en una casa de corrección o de expulsarla de la ciudad como se había viniendo haciendo desde tiempos atrás, se la recluía en una casa de prostitución limitando su libertad de circulación y controlando periódicamente su potencial capacidad de contagio venéreo.

$Y$ finalmente, la estrecha relación entre café cantante y prostitución también había sido puesta de realce en varios trabajos más o menos recientes, pero no siempre en la perspectiva de la sociabilidad ${ }^{15}$.

\section{«IR DE PUTAS». EL RITO DE LA VISITA COLECTIVA A LA «CASA DE PUTAS»}

Práctica habitual de colectivos varoniles solteros (como los militares) o rito de iniciación sexual para los jóvenes (verdadero «rito de paso»), la visita a las casas de prostitución (el «ir de putas», como vulgarmente se suele decir) formaba parte integrante del espacio sexual de los varones hispánicos en la época

12 VÁzQuez García, Francisco y MOREno Mengíbar, Andrés: Poder y prostitución en Sevilla (Siglos XIV al XX). Tomo II. La edad contemporánea, Sevilla, Universidad de Sevilla (Colección de bolsillo, $\left.n^{\circ} 145\right), 1996$, p. 265.

13 VÁzQUEZ GARCíA, Francisco: "Tras la cancela»: Sevilla en la edad de oro del burdel (18601936)", en Jornadas sobre los espacios de la sociabilidad sevillana. Sevilla, 7 al 9 de octubre de 1997, Sevi1la, Fundación El Monte (Colección «Ciclos», n 20), 1998, pp. 71-120.

14 GuEREÑA, Jean-Louis: «La sociabilité au quotidien. L'espace urbain madrilène au XIX ${ }^{e}$ siècle», en MARTín, Luis P. y Brenot Anne M. (Eds.): Les sociabilités dans le monde hispanique (XVIII ${ }^{\text {ime }}$ $X X^{\text {ime }}$ siècles). Formes, lieux et représentations, Valenciennes, Presses Universitaires de Valenciennes (Recherches Valenciennes 3), 2000, pp. 235-250.

is Blas Vega, José: Los cafés cantantes de Sevilla, Madrid, Editorial Cinterco, 1984, 102 p.; SALAÜN, Serge: «Sexo y canción (Prostitución y espectáculos en los siglos XIX y XX)», El Bosque, Zaragoza, $\mathrm{n}^{\circ}$ 2, Mayo-Agosto de 1992, pp. 107-121; VÁzQUeZ GARCía, Francisco y MORENO MENGíBAR, Andrés: Poder y prostitución en Sevilla, op. cit., pp. 201-210.

Hispania, LXIII/2, núm. 214 (2003) 551-570 
contemporánea pero también se enmarcaba en sus espacios habituales de ocio y de sociabilidad dada la estrecha imbricación en el marco urbano entre espacios prostitucionales y espacios festivos (tabernas, cafés cantantes, salas de fiesta...). Y junto a tales establecimientos característicos de la «vida nocturna», las Guías nocturnas que empezaron entonces a hacer su aparición en las grandes ciudades españolas en los años treinta incluían también señas y precios de "Maisons meubles y casas discretas autorizadas» ${ }^{16}$.

La visita a un prostíbulo concluía a menudo una tarde de juerga iniciada entre amigos en un espacio festivo de sociabilidad. «La fiesta consistía, primordialmente, en irse de putas», confiesa por ejemplo Juan Antonio Bardem en su interesante testimonio ${ }^{17}$. Y en su novela La orgía, centrada sobre la Sevilla de las dos primeras décadas del siglo XX, José Más relata, al referirse al café Novedades, la clara vinculación existente entre cafés cantantes y burdeles sevillanos en el mismo casco urbano de la capital andaluza:

«Hallábase situado el café en el centro de Sevilla, a dos pasos de la calle Sierpes, lindando con la celebrada taberna «La Campanilla», y en las proximidades de una calle misteriosa, tétrica y vergonzante. Callejuela donde se ocultaban todos los vicios y que, por contraste irónico, tenía este bello nombre, ensoñador y místico: Pasión. Por sus tenebrosas encrucijadas perdíanse muchos de los espectadores del café cantante cuando daba término la sección [sic] donde habían sido despertados sus instintos de macho. Casi siempre eran gentes de pueblo, impacientadas por extinguir la llama erótica que hacía vibrar sus nervios llenándoles el cerebro de imágenes obscenas» ${ }^{18}$.

Aunque de manera mucho más discreta que en otros países (como en Francia por ejemplo, donde se lo conocía por sus farolillos rojos y sus grandes rótulos), pero no menos real, el burdel tolerado (junto con otras formas de prostitución como las casas de cita y la prostitución «clandestina» a la que no cabe olvidar) formó en efecto plenamente parte del espacio urbano y social español dentro de lo que podemos considerar como la «edad de plata» de la prostitución reglamentada (de mediados del siglo XIX a 1935 y de 1941 a 1956) tras la que fue en cierto modo una «edad de oro» en la época medieval y moderna ${ }^{19}$.

La topografía prostitucional mantuvo además por lo general hasta hace poco sus espacios tradicionales dentro de los cascos urbanos o en determinados «barrios reservados», más o menos apartados, como los famosos «Barrio chino» barcelonés (o barrio del Raval) ${ }^{20}$, el «Molinete» cartagenero ${ }^{21}$, o el no menos

16 Guia Madrid de noche patentada con el $n^{0} 83504$, Año V, Madrid, 1935, pp. 73-92.

17 BARDEM, Juan Antonio: Y todavía sigue. Memorias de un bombre de cine, Barcelona, Ediciones B, 2002, p. 128.

18 MAS, José: La orgía, $6^{a}$ ed., Madrid, V. H. de Sanz Calleja, s.f., pp. 30-31.

19 GUEREÑA, Jean-Louis: La prostitución en la España contemporánea, Madrid, Marcial Pons, 2003.

20 VILlaR, Paco: Historia y leyenda del Barrio chino (1900-1992). Crónica y documentos de los bajos fondos de Barcelona, Barcelona, Edicions La Campana, 1996, 259 p.

Hispania, LXIII/2, núm. 214 (2003) \$51-570 
conocido «Alto de la Villa» albacetense ${ }^{22}$, que siguieron conservando por entonces sus características tradicionales de barrios «de vida alegre» (por lo menos antes de su destrucción).

En estos espacios de máxima concentración prostitucional, eran frecuentes los «paseos» de clientes potenciales o meros curiosos por las calles en las que se ubicaban las múltiples casas de prostitución, descritas por ejemplo para la Barcelona de postguerra por el editor y poeta barcelonés Carlos Barral:

«Era tal la concentración de burdeles y de putas por los alrededores de la desembocadura de las Ramblas, que ese barrio, aparte de contener una atmósfera muy particular, seminal y anaerótica, invitaba a una forma especial de paseo por calles, callejuelas, escaleras y rellanos. Una forma de paseo-inspección que practicaban centenares de ciudadanos, según uno se encontraba a las mismas gentes, repetidamente, en numerosos puntos del recorrido» ${ }^{23}$.

La afluencia a los prostíbulos era lógicamente mayor los fines de semana y en ocasiones festivas especiales, cuando se producían incluso verdaderas colas en torno a ellos:

«Eran días de sorteo de quintas, de manifestación de adhesión organizada, de partido de futbol, de corrida de feria... cuando de la provincia toda se desplazaban en trenes y camiones los machos, dispuestos a cumplir con un tributo tan tradicional y consabido que en la misma cola podían encontrarse padres, hijos, tíos, sobrinos y, en ocasiones, hasta los representantes de tres generaciones de una misma familia» ${ }^{24}$.

La localización de la actividad prostitucional dentro del espacio urbano fue precisamente el motivo de numerosas quejas vecinales a lo largo de la segunda mitad del siglo XIX y principios del XX, pese a que la reglamentación en vigor prohibía tajantemente en principio la existencia de burdeles junto a escuelas o iglesias..., prohibiciones no obstante sistemáticamente transgredidas.

En Burgos por ejemplo, unos 58 vecinos encabezados por Toribio Bartolomé y Parra, «que ven con profundo sentimiento entronizada, protegida y hasta

21 Rodríguez Cánovas, José: El Molinete de Cartagena. Apuntes para su historia, Dibujos de NAvarro, Enrique G., Prólogo de ColaO, Alberto, Cartagena, Athenas Ediciones (Colección Armajal, 27), 1970, 93 p.; LÓPEZ PAREDES, Manuel: Historias del Molinete de Cartagena, Alcoy, Gráficas Ciudad, S.A., 1986, 78 p.; EGEA BRUNO, Pedro María: «Moralidad, orden público y prostitución. Cartagena (1939-1956)", en SANTACREU SOLER J. M. (Ed.): Las transiciones políticas. II Jornadas internacionales sobre bistoria contemporánea y nuevas fuentes, Alicante, Editorial Club Universitario, 1997, pp. 161-173.

22 HeRAS GIL, Emilio: Estampas del Alto de la Villa: la prostitución arma destructiva de la bumanidad, s.l. (Albacete), s. ed. [Autor], 1978, 157 p.

23 BARral, Carlos: Años de penitencia, Madrid, Alianza Editorial, $3^{\text {a }}$ ed., 1976 [1975], p. 128.

24 SAIZ Viadero, J. R.: Conversaciones con la Mary Loly. 40 años de prostitución en España, Barcelona, Ediciones 29, 1976, p. 36.

Hispania, LXIII/2, núm. 214 (2003) 551-570 
legalizada, la prostitución con todas sus más perniciosas consecuencias, en esta Ciudad, y principalmente en la calle de la Puebla (que es una de las más públicas y de las más céntricas); y en frente y a las inmediaciones de Colegios de primera y de segunda enseñanza; con daño de la juventud, y contra lo que, aun tolerándose, está dispuesto», intentaban convencer en Junio de 1871 al Ayuntamiento burgalés de la necesidad de «dar inmediatamente las órdenes oportunas para que la escandalosa e inmoral prostitución traslade su residencia a las calles más apartadas y excéntricas, según está mandado cuando se tolera; si es` que no hay derecho a esperar que se persiga tenazmente hasta su completa extinción» ${ }^{25}$. También solicitaban la formación de una Comisión municipal para que «estudiando detenidamente el asunto», informe «si es prudente consentir la prostitución; si es moral considerarla como un modus vivendi legal, y si no altera, y si no pervierte los fundamentos de la sociedad y de la familia».

La cuestión de la localización de los espacios prostitucionales era pues central, tanto en el discurso reglamentarista como en la opinión pública ${ }^{26}$. En San Sebastián por ejemplo, a finales del siglo XIX, una parte de los prostíbulos se encontraba en la parte vieja (Plazuela de las escuelas, hoy Plaza de Sarriegui; Calle Treinta y uno de Agosto; Calle de la Zurriola) y otra en los suburbios que a principios del siglo XX iban a formar el nuevo centro urbano donostiarra y el barrio Gros (Calle Miracruz, Calle Camino, Calle del ferrocarril), o sea en zonas con fuerte densidad de población o en vías de serlo ${ }^{27}$.

Lógicamente, la oferta prostitucional intentaba acercarse a las zonas de mayor demanda potencial, lo que las autoridades municipales o provinciales pretendían impedir sin grandes resultados. En otros casos, la concentración prostitucional era total, no sólo en un barrio, que se convertía entonces en una especie de ghetto, sino incluso en una misma calle. Era por ejemplo el caso de Sueca (en la provincia de Valencia, 17.521 habitantes en 1930) en donde los siete burdeles tolerados que existían en 1929 estaban situados en la sola calle Levante ${ }^{28}$.

Un caso particular fue desde luego el de La Línea de la Concepción (Cádiz) donde, tras la abolición de la prostitución en el Peñón gibraltareño en la década de los veinte, las profesionales, británicas o españolas, se trasladaron a la vecina ciudad gaditana, "colonizando" toda una calle, la de Gibraltar, que apunta directamente al Peñón ${ }^{29}$.

Todavía en la Segunda República, las quejas y peticiones colectivas de vecinos domiciliados en espacios dedicados tradicionalmente a la prostitución no

25 Instancia de varios vecinos al Ayuntamiento de Burgos, 15-VI-1871 (A.M. de Burgos, Policía Urbana, Leg. $\mathrm{n}^{\circ}$ 922).

26 Ver, sobre el caso sevillano, VÁzQuez GarCía Francisco y MOReno Mengíbar Andrés: Poder y prostitución en Sevilla, op. cit., pp. 251-253.

27 BASTERRA, Pierre: La prostitution à Saint-Sébastien (Guipúzcoa) entre 1832 et 1920 à travers l'étude des archives municipales, Memoria de D.E.A., Universidad de París VIII, 1993, pp. 9-11.

28. «Profilaxis. Reconocimientos. 1929» (A.M. de Sueca, Sanidad, Caja n ${ }^{\circ}$ ).

29 STEWART, John D.: Gibraltar Piedra Clave, Madrid, Editorial Aguilar, 1968, p. 263. 
cesaban de llegar a los despachos de los Alcaldes y Gobernadores civiles, pero, lo que era nuevo, ya venían firmadas también por mujeres. En Noviembre de 1931, 45 habitantes (24 varones y 21 mujeres) de Zalamea la Real en la provincia de Huelva (11.418 habitantes en 1930) pedían así «que se ponga enmienda en la calle porque esto es un escándalo sobre las casas de prostitución que en lugar de que esas casas se desaparezcan que es al contrario que lo hacen es aumentarlas» ${ }^{30}$.

En la misma localidad, otra petición no fechada de 37 vecinos ( 21 mujeres y 16 hombres) pidiendo «justicia», se inscribía claramente en los nuevos tiempos republicanos:

«Tenemos que advertir que vivimos aquí forzozamente, unos por ser casa propia y otros no encontramos otra calle. Pero esto se hubiera terminado en cuanto viviera en dicha calle un burgués, porque del barrio de la estación Don Manuel Vázquez las quitó él sólo. Y sin molestar más advertimos que los vecinos de la calle Matadero no piden favor sino justicia»" 31 .

Como en otros lugares y en otras épocas, no se cuestionaba de ningún modo la existencia de tales casas de prostitución sino su visibilidad considerada excesiva y lo único que se reclamaba era su deslocalización. Ante tan reiterativas protestas, y para quitarse el problema de encima, el Ayuntamiento decidió sencillamente prohibirlas. Pero este acuerdo no estuvo del gusto de todos y motivó una nueva e insólita petición de 30 varones «jóvenes» de la localidad (todos firmando con nombre y apellido salvo el caso de «un simpatizante») solicitando su revocación:

«Enterados que por acuerdo de esa Corporación se ha acordado que no haya mujeres de las que nosotros los jóvenes deseamos, tenga $\mathrm{V}$. un poco de benevolencia, puesto que son días de ferias y eso es propio para la expansión de los jóvenes» ${ }^{32}$.

El Ayuntamiento dio marcha atrás y sólo entonces un concejal propuso regularizar la situación desde un punto de vista sanitario, introduciendo reglas mínimas «conducentes a evitar en lo posible el $[\ldots .$.$] contagio de las enfermeda-$ des venéreas» ${ }^{33}$

En días de ferias o no, la necesidad del prostíbulo venía pues reivindicada por los jóvenes mismos que a menudo realizaban allí su primera experiencia

30 Instancia colectiva al Alcalde de Zalamea la Real, 26-XI-1931 (A.H.P. de Huelva, Fondos municipales. Zalamea, 1931). Se conserva la sintaxis del documento. Ver CARRASCO PerEA, Sebastián: «Las pupilas», Revista de Feria de Zalamea la Real, Zalamea la Real, III ${ }^{a}$ Ép., Vol. II, nº 12 , 1990 , pp. 15-17.

31 Instancia colectiva al Alcalde de Zalamea la Real «y a todos los concejales», s.f. [¿1931?] (A.H.P. de Huelva, Fondos municipales. Zalamea, 1931).

32 Instancia colectiva al Alcalde de Zalamea la Real, s.f. [¿1931?] (Ibid.).

33 Moción del concejal Manuel Domínguez de la Banda, s.f. [¿1931?] (Ibid.).

Hispania, LXIII/2, núm. 214 (2003) 551-570 
sexual en una visita colectiva. A principios de los años veinte, el poeta Rafael Alberti [1902-1999] conoce así en Málaga su primer burdel, "un precioso prostíbulo cercano al mar», en compañía de «aquellos hoy borrados amigos, insoportables señoritos de la buena sociedad malagueña»:

«No sin cierto temor, que perdí a los pocos minutos, penetré -era la primera vez que lo hacía - en aquella casa mediterránea de Venus, verdadero jardín donde sus morenas hijas andaluzas resaltaban, casi desceñidas de velo, entre macetas de geranios y claveles violentos, el mareante aroma de las albahacas, magnolios y jazmines» ${ }^{34}$.

Sobre la postguerra, los años cuarenta y cincuenta del siglo XX, también disponemos de algunos testimonios, como el del cineasta Juan Antonio Bardem, nacido en 1922, sobre la práctica iniciática de «pandillas» juveniles acudiendo a los burdeles:

«Una vez mi pandilla hizo acopio de todo su valor y nos fuimos a una «casa de putas». Nuestro mentor era otro compañero del instituto que había estado allí otra vez» 35 .

Del mismo modo, Carlos Barral, nacido en 1928, precisa que visitó hacia 1944 «aquellos envejecidos nidos de amor venal, sobre todo en grupo, y, como dirían las muchachas, en plan de cachondeo, tal vez a jugar a las cartas y a beber un coñac miserable con gusto a barniz ácido» ${ }^{36}$. Otro testimonio indica que su primera visita a un burdel «fue hacia los quince o dieciséis años, durante el verano... en Santander»:

«Fue una experiencia de iniciación colectiva, grupal. Después de las consabidas copas, fuimos con unos amigos a un burdel provinciano» 37 .

El «ir de putas» (con un sinfin de expresiones eufemísticas, tal «ir de picos pardos», «echar un polvete» o "echar una cana al aire»), de forma ocasional o con relativa frecuencia, en solitario y sobre todo en pandilla, era entonces socialmente aceptado y plenamente practicado ${ }^{38}$, sea por los colectivos masculinos desprovistos de pareja estable, los jóvenes solteros con o sin novia, los viu-

\footnotetext{
34 AlberTi, Rafael: La arboleda perdida. Libros I y II de Memorias, Buenos Aires, Compañía General Fabril Editora, 195.9, p. 123.

35 BARDEM, Juan Antonio: Y todavía sigue, op. cit., p. 126.

36 BARRAL, Carlos: Años de penitencia, op. cit., p. 115.

37 Testimonio de Corcés Pando, Valentín en OTERo Pizarro Gonzalo y NATuCCI Osvaldo: Las prostitutas y yo, Barcelona, Editorial Bruguera, 1978, p. 62.

38 Ver WerRIE, Paul: L'amour à Cespagnole, Paris, La Table Ronde, 1964, p. 225 (existe traducción española: El amor a la española, Barcelona, Sagitario Ed., 1971), y BARDEM, Juan Antonio: Y todavía sigue, op. cit., p. 69.

Hispania, LXIII/2, núm. 214 (2003) 551-570
} 
dos o también los casados más o menos frustrados sexualmente por su pareja, incluso si la oprobia y el estigma tradicionales hacia las prostitutas (de la que testimonia con creces el lenguaje coloquial) seguían particularmente vivos en la sociedad española. No cabe duda de que la institución social del noviazgo largo junto con la alta valoración social de la virginidad femenina y el culto de la virilidad (el famoso machismo hispánico), favorecieron indudablemente las prácticas prostitucionales, en particular como forma de iniciación sexual para los jóvenes varones ${ }^{39}$ :

«La tónica general entre adolescentes y jóvenes era ir el domingo «de pu». En los prostíbulos había enormes colas» ${ }^{40}$.

Tradicionalmente pues, las prostitutas servían de iniciadoras sexuales a los varones españoles. Según la encuesta llevada a cabo en los años sesenta por Lidia Falcón y Eliseo Bayo acerca del comportamiento sexual del varón barcelonés, en un $62 \%$ de los casos la prostituta aparecía como protagonista de la primera experiencia sexual, verificada entre los 14 y los 20 años ${ }^{41}$. Y en algunos talleres, hasta se realizaban colectas entre los obreros mayores "para cubrir los gastos que origina un ambiente económico de prostitución para que el aprendiz fuese tomando experiencias de la vida» ${ }^{42}$.

\section{«TRAS LA CANDELA». EL «SALÓN» DEL PROSTÍBULO COMO ESPACIO DE RECREO}

La visita masculina a las casas de prostitución toleradas se presentaba pues como un rito que solía realizarse en grupo o a iniciativa de un colectivo. Y una vez en el burdel, «las pupilas, emplazadas tras la cancela candada, eran expuestas en venta ante la mirada colectiva de los clientes» ${ }^{43}$.

Interrogado por dos periodistas, el novelista Juan Marsé recuerda sus primeras visitas a los prostíbulos baratos del Barrio Chino barcelonés hacia 1947 —establecimientos como La Maña o El Jardín— que se reducían de hecho a

39 MaRtín Gaite, Carmen:: Usos amorosos de la postguerra española, Barcelona, Anagrama, 1982, 443 p.; CRÉACH, Jean: Chroniques espagnoles. Le coeur et l'épée, Paris, Librairie Plon, 1958, Pp. 98-99; WERRIE, Paul: L'amour à lespagnole, op. cit., pp. 54-77 («La virginité, cette «folie»).

40 CANDEL, Francisco: Ser obrero no es ninguna ganga, Barcelona, Ediciones Ariel, 1968, pp. 226 y 228 .

41 Índice, Enero de 1967, cit. por LATORRE, Joaquín: Los españoles y el VI mandamiento, Barcelona, Ediciones 29, 1969, p. 32.

42 J. M. S., «Rincón del aprendiz», Juventud Obrera, n 75 , Julio de 1963, cit. por CANDEL, Francisco: Ser obrero no es ninguna ganga, op. cit., p. 223.

43 MORENO Mengíbar, Andrés: «Crisis y transformación de la prostitución en Sevilla (18851920)», Bulletin d'Histoire Contemporaine de lEspagne, Aix-en-Provence, no 25, Junio de 1997 [Prostitución y sociedad en España. Siglos XIX y XX], p. 126. 
«un salón sórdido y bastante grande», donde «ellas estaban sentadas en una especie de banquetas» ${ }^{44}$.

El «salón» del prostíbulo, por supuesto más o menos lujoso y cómodo según la categoría del establecimiento, representaba pues el espacio central del mismo en donde se efectuaba el primer encuentro entre el cliente y la prostituta mediante el proceso de «selección», pero al mismo tiempo funcionaba como un verdadero lugar de vida colectiva, donde también los hombres venían a hablar, a beber, a fumar, a jugar a las cartas..., o sencillamente a echar una ojeada a lo que conservaba parte de misterio y de morbo y seguía objeto de innumerables fantasías masculinas.

A menudo descrito en varios testimonios, el salón, sala de espera pero también sala de estar o de recreo, desempeñaba por lo tanto un papel esencial desde el punto de vista de la sociabilidad masculina, pues se trataba aún de un espacio público en cierto modo, abierto a todos los hombres, antes de proceder a la elección (en principio individual) de la prostituta para un acto sexual.

En 1938, la pandilla de Bachillerato de Bardem, residente entonces en San Sebastián con su familia, decidió así acercarse una tarde a una «casa de putas» donostiarra cuyo salón nos describe con precisión:

«Una pequeña sala de paredes desnudas pintadas de amarillo con un zócalo verde al que se adosaba un banco corrido de madera, también pintado de verde, mesas, sillas y veladores en el centro. $Y$ algo como un bar en uno de los lados. [...].

En otra de las paredes había una escalera de madera, pintada de marrón, que subía hasta la planta superior y daba paso, seguramente, a los cuartos donde se iniciaba el viaje a Citerea»45.

Inmediatamente, el paralelo con el círculo de recreo o con el café puede aparecer evidente. El principio del consumo sexual, inscrito desde luego explícitamente en la entrada al burdel (y que fundamenta su diferencia), se acompañaba sin embargo o dejaba paso incluso a otras prácticas de sociabilidad más o menos implícitas. El burdel no significaba en efecto solamente un lugar de encuentros sexuales venales sino también un lugar de la sociabilidad local, como un café por ejemplo, y en donde, mediante el precio de alguna bebida pero a veces ni eso, los hombres podían encontrarse en galante compañía sin sentirse obligados de "consumir» sexualmente.

El testimonio de Carlos Barral sobre algunos de los prostíbulos barceloneses de postguerra es revelador al respecto:

«En la sala había unas cuantas sillas, alguna gente ocupándolas, muchos de pie, inmóviles, y el trasiego incesante de los que entraban a echar una ojeada y salían sin detenerse. Los habituales procuraban sentarse y fumar por lo menos un

44 OTero Pizarro Gonzalo y NATUCCI, Osvaldo: Las prostitutas y yo, op. cit., p. 149.

45 BARDEM, Juan Antonio: Y todavía sigue, op. cit., p. 126. 
cigarrillo. Se estaba bien allí, calentito, no costaba nada y era divertido. Los habituales eran, sobre todo, gente madura con aire de derrotados y dispuestos a aguantar las bromas y las impertinencias de las mujeres que se consideraban perjudicadas por su demorada presencias ${ }^{46}$.

Las prostitutas calificaban a aquellos meros visitantes de los burdeles (los que no «subían» con las mujeres y no eran pues clientes potenciales e ininteresantes) del mote despectivo de «floreros». Y, según el mismo testimonio, otros prostíbulos barceloneses de los años cuarenta tenían incluso un ambiente casi familiar, y se podía ir allí hasta a jugar a las cartas:

«También había prostíbulos que conservaban intacta la decoración y la estructura de la casa de familia de barrio, prostíbulos como de pueblo, en los que las putas recibían alrededor de una mesa de comedor bajo una lámpara central aderezada con unas zayas rojas. La mesa influía las costumbres; las de comedor eran casas de putas a las que podía ir a jugar a las cartas a la tercera o cuarta visita ${ }^{47}$.

Algunos prostíbulos de mayor categoría pretendían asimilarse más o menos a interiores burgueses. El autor anónimo de la comedia La Tripona o la Casa de Trato, publicada clandestinamente en 1850, sitúa por ejemplo la acción de la obra, ambientada en Cádiz, en el «salón decentemente amueblado de la casa de la Tripona» por el que desfilan prostitutas y clientes ${ }^{48}$. Y, a propósito de Sevilla, señalaba en 1918 el ya mencionado José Mas en La orgía que «algunas veces, dentro de aquellas viviendas tan silenciosas, tan apacibles, tan artísticamente alhajadas, el visitante se sugestionaba y creía que, por un error involuntario, se había introducido en el hogar de una honrada burguesa» ${ }^{49}$.

Sea cual sea su nivel social y sus gustos, el cliente podía llegar a sentirse pues en el burdel como en su casa, junto a amigos. El novelista Fernando Vizcaíno Casas, que ha retratado la prostitución en su novela Niñas... ial salón!50, cuenta también en sus memorias que «en algunas casas de prostitución había piano y clientes que no tenían el menor reparo en sentarse frente al teclado para tocar el Ave María de Gounod, que gustaba mucho a las chicas» ${ }^{51}$.

$\mathrm{Y}$ en su pintoresca y detallada visita a los burdeles almerienses en los años veinte publicada por primera vez en inglés en 1957, el hispanista inglés Gerald Brenan [1894-1987] ya describía, no sin sorpresa suya, varios «salones» de

46 BARRAL, Carlos: Años de penitencia, op. cit., p: 125.

47 Ibid., p. 126.

48 La Tripona o la Casa de Trato. Comedia en un acto original y en verso, Bayona, Imprenta de Jodiguelos, a cargo de don Cipote, 1850, $32 \mathrm{p}$.

49 MAS, José: La orgía, op. cit., p. 90.

so Vizcaíno CASAS, Fernando: Niñas... ial salón!, Prólogo de IBÁñEz SERRAdor, Narciso, Barcelona, Editorial Planeta (Colección Fábula), 4a ed., 1976, 234 p.

51 Vizcaíno CaSAS, F.: Los pasos contados. Memorias I, Barcelona, Planeta, 2000, p. 254. 
burdeles populares incidiendo en esta fuerte dimensión de sociabilidad que descubría cada vez que entraba en uno de aquellos prostíbulos:

«Llamamos a la puerta de una casa que estaba a corta distancia. En el pequeño salón, dos hombres, sentados, estaban bebiendo con tres chicas [...]. Tenían el aspecto de ser clientes habituales, y efectivamente [...] eran tenderos del mercado que venían todas las semanas. La política volvió a surgir, y aquí todos, incluida el ama $[\ldots]$ estaban por la república»;

«[...] Para los clientes ordinarios, el salón era suficiente; aquí se sentaban y bebían hasta que se armaban de valor para llevar su visita un paso adelante, o se marchaban. Exceptuando que las mujeres iban ligeras de ropa, la atmósfera no podía ser más decorosa. Los hombres hablaban entre sí manteniéndose juntos como para afirmarse, haciendo poco caso a las figuras caprichosamente vestidas que se sentaban bostezando a su lado [...]”;

«Lo mismo podíamos haber estado sentados en un café, ya que los hombres estaban hablando entre sí, sin mostrar más que un interés esporádico por las chicas que se sentaban con sus ligeros vestidos juntos a ellos» ${ }^{52}$.

«Lo mismo podíamos haber estado sentados en un café»: la comparación no puede ser más reveladora de la multifuncionalidad del burdel y la frontera entre ambos espacios menos tenue.

Nos parece pues claro, a luz de estos diversos testimonios, que el burdel; así como la misma calle o el barrio en los cuales se ubicaba, funcionaba de hecho como un espacio de sociabilidad masculina muy similar a otros a los cuales los historiadores de la sociabilidad han prestado mayor atención. Pero se trataba también de una concentración de varias mujeres que cohabitaban juntas en un mismo espacio.

\section{UN ESPACIO DE SOCIABILIDAD FEMENINA. LA VIDA COTIDIANA EN EL BURDEL}

La sociabilidad femenina en el medio prostitucional apenas ha sido tratada por los historiadores, y no sólo por falta de fuentes documentales ${ }^{53}$. Se han realizado sin embargo algunas aproximaciones de corte sociológico a la población prostitucional ${ }^{54}$. Más raramente se ha intentado un acercamiento a la topografía y a la morfología de la prostitución adaptadas a la demanda sexual y casi nunca una introspección de la vida cotidiana de las prostitutas y de sus relaciones con la clientela, así como estrategias profesionales o lo que Francisco

52 BrenaN, Gerald: Al Sur de Granada, Traducción de CHAmorro, Eduardo y VilLA, Jesús, Barcelona, Tusquets Editores (Fábula, 79), $4^{\mathrm{a}}$ ed. en Fábula, 2002 [1 $1^{\mathrm{a}}$ ed. inglesa, 1957], pp. 247, 251 y 254

53. VÁZQUEZ, Francisco J.: «Tras la cancela», op. cit., pp. 108-117.

54 GUEREÑA, Jean-Louis: «Una aproximación sociológica a la prostitución», Historiar, Barcelona, $\mathrm{n}^{\circ} 2$, Julio de 1999 [Dossier La prostitución en la España contemporánea], pp. 12-23.

Hispania, LXIII/2, núm. 214 (2003) 551-570 
Vázquez ha calificado de "prácticas de supervivencia» que estructuraban el espacio femenino del burdel en relación con los modos de regulación social que se les intentaba imponer, como por ejemplo «la capacidad de estas mujeres para ajustar el tiempo de la oferta al de la demanda» $\$ 5$.

En un texto - -una propuesta de reglamentación de la prostitución en diecinueve medidas - escrito por el médico afrancesado Antonio Cibat [17711811 ] en 1809 , pero entonces no publicado que sepamos, y por lo tanto pasado totalmente desapercibido, incluso tras su publicación en $1861^{56}$, se reconocía claramente la utilidad social de la prostitución, considerada como un «oficio» específico, ejercido más o menos "dignamente», y se evocaba, de modo totalmente nuevo, el papel de las casas de prostitución como verdaderos espacios de sociabilidad donde el sexo venal no era sino un aspecto de la relación, si bien dominaba la perspectiva sanitaria e inmunitaria.

Se aconsejaba precisamente a los prostitutas que estaban «solas, o aisladás en sus cuartos o alojamientos» agruparse «tres, cuatro o más en una misma casa, que dirijidas por una mujer de respeto, sostenida y apoyada por la garantía del Gobierno, pudiera defenderlas [...]» de las «tropelías infames o indecorosas» cometidas por «algunos jóvenes precipitados [...] olvidados de los respetos que deben al sexo débil» (punto $10^{\circ}$ ). Solución a la que debía contribuir el Gobierno "por el bien que que produciría a la sociedad y al Estado», o sea un mejor control de la situación (punto $12^{\circ}$ ).

El burdel venía a presentarse incluso como un verdadero establecimiento de educación y las prostitutas como auténticas «educandas»; en quienes las directoras, «si $[\ldots .$.$] fuesen mujeres de alguna educación», «inspirasen buenos senti-$ mientos» (punto $10^{\circ}$ ). Lo cual implicaba cierta elección «con la mayor escrupulosidad» de las directoras por la policía que había de protegerlas (punto $13^{\circ}$ ).

Entonces, en estos burdeles new look, y según palabras de Cibat, las prostitutas convertidas en auténticas geishas, "reunidas todas en sociedad, se harían más finas; tal vez se las excitaría el gusto a la lectura de buenos libros; aprovecharían y adelantarían en la labor y ocupaciones domésticas; en fin, podría resultar de esto que en lo sucesivo hallarían los hombres al visitarlas tanto gusto en sus conversaciones como en todo lo demás» (punto $11^{\circ}$ ). Atento como ya lo hemos apuntado a las cuestiones lexicales, Cibat proponía incluso cambiar el término de «burdel» (el único término clásico de la terminología prostitucional presente en este texto) por «otro que fuera más halagüeño a las que se dedican al comercio del amor» (punto $12^{\circ}$ ).

s5 VÁzQUEZ, Francisco J.: «Tras la cancela», op. cit., p. 109.

s6 «Medidas propuestas por D. Antonio Cibat para contener los progresos de la sífilis», El Siglo Médico, Madrid, t. VIII, n 379, 7-IV-1861, pp. 221-222. Ver GuEREÑA, Jean-Louis: Médicos y prostitución. Un proyecto de reglamentación de la prostitución en 1809: La «Exposición» de Antonio Cibat (1771-1811), Barcelona, Centro de Documentación de Historia de la Medicina de J. Uriach \& Cía (Medicina E Historia. Revista de estudios históricos de las Ciencias Médicas, $3^{\mathrm{a}}$ época, $\mathrm{n}^{\circ} 71$ ), 1998, $16 \mathrm{p}$.

Hispania, LXIII/2, núm. 214 (2003) 551-570 
En régimen de libertad vigilada, las prostitutas podían no obstante salir de las casas de prostitución pero «acompañadas de sus respectivas directoras», quedando autorizadas en separarse sólo «en el caso de hallar a algún contratante» (punto $16^{\circ}$ ).

Las obligaciones de cada parte venían definidas. Aunque algunas «son tan desidiosas, interesadas y miserables, que sólo tienen por objeto las ganancias que en su idea se han prometido hacer, y jamás acudir a los gastos a que están obligadas», las amas tenían el deber de facilitar a sus pupilas «cuartos mueblados con decoro", de "mantenerlas con decencia y vestirlas con limpieza y agradablemente» (punto $1^{\circ}$ ). La noción de limpieza y de aseo era esencial, pues se trataba según Cibat de «unos preservativos excelentes de los contagios». Las amas debían pues disponer que los cuartos tengan «jofaina, jarros con agua y toallas» para que las prostitutas y sus clientes "puedan limpiarse» (punto $17^{\circ}$ ). También debían de exigir cierta urbanidad en las prostitutas:

«[...] Ésta procurará que la buena compostura y decencia de sus educandas sea el objeto a que se dirijan todas sus miras, porque el donaire mal entendido e indecente y la voluptuosidad sin freno, no son los mejores excitantes de las pasiones amorosas" (punto $16^{\circ}$ ).

En la continuidad con otras medidas de sanidad pública, la restauración de la prostitución reglamentada implicaba una clara racionalización del espacio urbano: lugares y mujeres claramente identificados, señalados de modo inconfundible para facilitar su reconocimiento, especificados y controlados a fin de evitar desórdenes. Según este esquema, la «carrera» prostitucional se desarrollaría así en cuatro espacios totalmente acotados y perfectamente controlados por las autoridades, formando como una red institucional cerrada y cíclica ${ }^{57}$ : el burdel tolerado primero como espacio profesional y lugar de vida de las prostitutas, el hospital (en salas reservadas a los venéreos o en un establecimiento específico), la carcel de mujeres (la antigua "Galera»), y eventualmente la casa de recogidas para prostitutas «arrepentidas», construida claramente bajo el modelo conventual o carceral.

La situación política de España en aquel entonces no permitía desde luego la realización de tal proyecto, aunque parece ser que durante la ocupación francesa llegara a reglamentarse en la práctica la prostitución, pero seguramente con otras características que las ideales propuestas por Cibat.

Sobre la vida cotidiana de las prostitutas en el burdel, bien a la espera del cliente, bien fuera del tiempo de comercio sexual dentro de su tiempo libre, disponemos de pocos documentos. No obstante, las representaciones de pretensión naturalista, sean pictóricas o novelísticas, pueden suplir en parte esta carencia.

57 GATTEI, Giorgio: «Miseria sessuale e prostituzione», Studi Storici, Roma, vol. 21, 1980, $\mathrm{n}^{\circ}$, pp. 193-197.

Hispania, LXIII/2, núm. 214 (2003).551-570 
El cuadro de José María Romero y López, «Interior de un salón» o «Escena galante» (según los autores), tiene por ejemplo el interés de presentar el interior de un burdel sevillano en la época isabelina:

«[...] Interior de un salón, en este caso no burgués sino de uso público; se trata de una escena galante que acontece en un burdel donde cuatro alegres pupilas de bella presencia, al tiempo que fuman cigarros puros, charlan entre sí, mientras que otra joven galantea con un militar a través de una ventana; al fondo, la figura de otro militar sentado en el borde de una cama y abrazado a una joven no deja duda alguna sobre la índole del asunto representado en el cuadro» ${ }^{58}$.

La imagen del burdel que pretende ofrecernos el pintor sevillano es casi familiar, concordando con otros testimonios. Las pupilas están sorprendidas en sus rutinas cotidianas (fumar, bordar, conversar...) por la llegada de los militares, clientes potenciales, uno de los cuales está tal vez discutiendo el precio del servicio. La famosa fotografía de Luis Escobar («Señoritas de El alto de la villa») representando a un grupo de tres prostitutas albacetenses bebiendo anís y jugando a las cartas es otro testimonio muy posterior (1928) de prostitutas en la intimidad de su habitación, sorprendidas por el fotógrafos9.

A lo largo del amplio conjunto novelístico que dedica a la prostitución durante la Restauración - La prostituta. Novela médico-social (1884), La pálida (1884), La buscona (1885), La querida (1885) y Carne importada (Costumbres de Buenos Aires) ${ }^{60}$ - también presenta Eduardo López Bago [1855-1931] la vida cotidiana en un burdel madrileño (con y sin los clientes, como en el comedor, «el lugar destinado a los amigos de confianza de la casa» ${ }^{61}$, con las tertulias que allí se entablaban), la tipología de la población prostitucional (las pupilas, las amas, los chulos, los clientes), las diversas formas de la prostitución (clandestina y reglamentada), las causas que inducen a jóvenes mujeres a ingresar en este mundo, la reglamentación y la organización —incluso económica - a la que se somete tal actividad ${ }^{62}$.

58 VALDIVIESO, Enrique: «Sevilla pintada. 1790-1868», en Iconografía de Sevilla 1790-1868, Madrid, Ediciones El Viso, 1991, p. 130, lám. 110. Ver VÁzQUEZ, Francisco J.: «Tras la cancela», op. cit., pp. 95-96.

s9 Retratos de la vida 1875-1939. Fotografías de Luis Escobar y otros recopiladas y seleccionadas por Publio López Mondéjar, Prólogo de García Calvo Agustín, Madrid, H. Blume Ediciones, 1981, p. 97.

60 FERNÁNDEZ, Pura: Eduardo López Bago y el naturalismo radical. La novela y el mercado literario en el siglo XIX, Amsterdam-Atlanta, Ediciones Rodopi (Teoría literaria: Texto y Teoría, $\mathrm{n}^{\circ} 18$ ), 1995 , pp. 154-175, y «El eros prostituido de la novela naturalista», Historiar, Barcelona, $\mathrm{n}^{\circ} 2$ [Dossier La prostitución en la España contemporánea], Julio de 1999, pp. 71-83.

61 LóPez BAGo, Eduardo: La Prostituta. Novela médico-social, $4^{\mathrm{a}}$ ed. corregida, Madrid, Juan Muñoz y Compañía, Editores, s.f. [ $1^{\text {a }}$ ed., 1884], p. 140.

62 Ibid., pp. 42 y $52-53$. 
Bien nos muestra López Bago de paso la nueva personalidad que ha de adquirir la prostituta con su cartilla sanitaria así como los diversos espacios en los cuales se mueve en su actividad prostitucional:

«iEl lupanar! iSan Juan de Dios! iEl Gobierno Civil! Tres sitios en que la mujer es únicamente la hembra, en que se siente excluída de la raza humana, en que se ve tratada con el trato que recibe del hombre la animalidad [...], preocupándole únicamente la conservación de aquel cuerpo en estado de salud, no por atención a su vida, sino por la vida y la salud de los demás» ${ }^{63}$.

En un texto pornográfico clandestino de finales del siglo XIX, el autor anónimo da la palabra a las prostitutas que se quejan precisamente de estar relegadas a la mera categoría de mercancía:

«Nos consideran únicamente como instrumentos venales de sus placeres, y como nos retribuyen con el oro se creen dispensados de toda consideración y nosotras no tenemos el derecho de exigir mejor trato» ${ }^{64}$.

Finalmente, también habría que aludir a las estrategias de solidaridad profesional y a las prácticas de sociabilidad que podían establecerse entre prostitutas, tanto en el burdel como en la calle. Los facultativos encargados de las revisiones médicas a las prostitutas se quejaban en efecto a menudo de que las pupilas oficiales pasaban sus cartillas sanitarias a compañeras clandestinas o enfermas ${ }^{65}$. Frente a la policía, también se daban similares mecanismos de ayuda:

"Cuando vienen los guardias, para que no las lleven detenidas, corren y se avisan unas a otras. Así, que no es raro ver de pronto doce o quince mujeres, corriéndose y metiéndose en los portales, porque viene «la bofia» ${ }^{66}$.

Y, según el «estudio psico-sociológico» llevado a cabo a finales del siglo XIX en Madrid por Constancio Bernaldo de Quirós y José María Llanas Aguilaniedo, "las carreristas hacen también vida asociativa»:

«Los apodos dan fe de ello. Las bellezas de hospital, alcohólicas y sifilíticas, que tienen para sus relaciones con el público bonitos nombres en que se agotan las advocaciones de todas las vírgenes españolas y el santoral romántico y pretencioso de la busconería, las Floras, las Raquel, las Corales, las Virginias, las Palmiras, etc., conócense entre ellas y sus íntimos con apodos de gusto más vulgar y humilde: la Camporaso, la Cacharrito, la Minutos, la Corre-corre, la Nacha, la

63 Ibid., p. 44.

64 Las aventuras de un pollo. Cuadro de costumbres sociales por Uno que lo entiende, Olimpo, Imprenta Mitológica, 1882, p. 86.

65 VÁzQUEZ, Francisco J.: «Tras la cancela», op. cit., pp. 115-116.

66 BAREA, Arturo: La forja de un rebelde, México, Ediciones Montjuich, 1959, p. 148. 
Iluminada, la Cristiana, la Petaca, la Bicicleta, el Hurón, la Colilla, la Salerito, la Chico, etcétera, etc.»67.

Pero, a falta de diarios o de memorias íntimas como se han podido encontrar en otros países ${ }^{68}$, difícil resulta penetrar en la intimidad de las prostitutas, indagar en su vida cotidiana y sus prácticas de sociabilidad. Se trata pues solamente de meros apuntes que pretenden incidir en el tema.

Sean cuales sean sus formas y sus características, los espacios prostitucionales nos parecen formar parte integrante de las redes de sociabilidad masculina durante buena parte de la España contemporánea y también constituir el escenario de sociabilidades femeninas en el seno de las poblaciones prostitucionales.

Sin embargo, el contraste era ya tradicional en el seno de la sociedad hispana entre por una parte el rechazo social de las prostitutas, ilustrado en múltiples palabras y expresiones populares, y por otra la tolerancia generalizada de la prostitución, totalmente admitida e incluso defendida como necesidad social:

«Parécenos hoy tan natural la casa del mal vivir, gobernada y regida por los reglamentos de la higiene de la prostitución, cosa tan arraigada y naturalizada dentro de la vida social de las poblaciones, que de no haber casas públicas, sentiríamos la necesidad de ellas» ${ }^{69}$.

67 Bernaldo De Quirós, C. y Llanas Agullaniedo, J. Ma .: La mala vida en Madrid. Estudio psico-sociológico con dibujos y fotografías del natural, Madrid, B. Rodríguez Serra, Editor, 1901, pp. 253-254.

68 La novela de CHERNER, Matilde publicada bajo seudónimo masculino y que pretende relatar las «memorias íntimas» de una prostituta, no ofrece interés desde ese punto de vista (LUNA, Rafael: María Magdalena (estudio social), Madrid, Imp. y Fund. de la Viuda e Hijos de J. A. García, s.f. [c. 1880], 217 p.). Ver RodrígueZ SÁNCHEZ, $M^{a}$ de los Ángeles: «Matilde Cherner: una voz femenina y crítica ante la prostitución en la España de 1880», en SEvilla Florencio y Alvar Carlos (Eds.): Actas del XIII Congreso de la Asociación Internacional de Hispanistas Madrid, 6-11 de Julio de 1998, Madrid, Asociación Internacional de Hispanistas-Editorial Castalia-Fundación Duques de Soria, vol. II (Siglos XVIII. Siglo XIX. Siglo XX), 2000, pp. 370-378.

69 Domingo Calvo, Félix: La mujer mala y los males secretos, Valladolid, Talleres Tipográficos «Cuesta», 1917, p. 3.

Hispania, LXIII/2, núm. 214 (2003) 551-570 